\title{
Frontières
}

\section{Quelques réflexions de... Micheline de Sève}

\section{Micheline de Sève}

Volume 12, numéro 1, automne 1999

Suicides, générations et culture

URI : https://id.erudit.org/iderudit/1075916ar

DOI : https://doi.org/10.7202/1075916ar

Aller au sommaire du numéro

Éditeur(s)

Université du Québec à Montréal

ISSN

1180-3479 (imprimé)

1916-0976 (numérique)

Découvrir la revue

Citer ce document

de Sève, M. (1999). Quelques réflexions de... Micheline de Sève. Frontières, 12(1), 14-14. https://doi.org/10.7202/1075916ar d'utilisation que vous pouvez consulter en ligne.

https://apropos.erudit.org/fr/usagers/politique-dutilisation/ 


\section{Quelques réflexions de... Micheline de Sève}

professeure au Département de science politique, directrice de I'Institut de recherche et d'études féministes, UQAM.

Santé, emploi, amis, amour. Deuils multiples. Quand l'espoir s'effiloche, la vie devient friable. Se tuer, ce peut être le choix d'une euthanasie précoce, c'est surtout le constat, rationnel ou non, d'un blocage absolu de l'horizon, humainement insupportable. Quand le quotidien n'est plus que fardeau, le dégoût de soi comme de l'entourage tue. Quelle dignité garder dans ces démarches qui vous ballottent d'un guichet à l'autre, accroc de l'offre illusoire de secours extérieurs, en manque de reconnaissance? Tenu à distance de soi, privé des moyens de l'être, qui viendra repêcher celui ou celle que la détresse affole? Résister à l'appel de mort n'est pas simple dans un milieu en perte de sens, sourd à ce qui sort de l'ordre technique des casiers fonctionnels à gérer. Inconvenant, l'appel à l'aide, le cri dément, s'étrangle dans la ouate du sourire de commande des gens «normaux», ces hommes et ces femmes qui débitent le malheur en tranches, sur rendez-vous, du lundi au vendredi, dans le mépris de l'indifférence ou le ras-le-bol des fonctionnaires de l'âme, piégés par le surmenage. Civilisation dites-vous? 